\title{
Prognostic value of chemotherapy in addition to concurrent chemoradiotherapy in T3-4NO-1 nasopharyngeal carcinoma: a propensity score matching study
}

\section{Li-Rong Wu ${ }^{1}$, Hong-Liang $\mathbf{Y u}^{1}{ }^{1}, \mathrm{Ning}$ Jiang $^{1}$, Xue-Song Jiang ${ }^{1}$, Dan Zong ${ }^{1}$, Jing Wen ${ }^{1}$, Lei Huang ${ }^{1}$, Peng Xie ${ }^{1}$, Wei Chen ${ }^{1}$, Ting-Ting Wang ${ }^{1}$, Da-Yong Gu ${ }^{1}$, Peng-Wei Yan ${ }^{1}$, Li Yin ${ }^{1}$ and Xia $\mathrm{He}^{1}$}

\begin{abstract}
${ }^{1}$ Department of Radiation Oncology, Nanjing Medical University Affiliated Cancer Hospital, Jiangsu Cancer Hospital and Jiangsu Institute of Cancer Research, Nanjing 210009, China

Correspondence to: Xia He, email: hexia206@yeah.net

Keywords: nasopharyngeal carcinoma, concurrent chemoradiotherapy, induction chemotherapy, adjuvant chemotherapy, prognosis

Received: April 05, $2017 \quad$ Accepted: June 30, $2017 \quad$ Published: August 07, 2017

Copyright: Wu et al. This is an open-access article distributed under the terms of the Creative Commons Attribution License 3.0 (CC BY 3.0), which permits unrestricted use, distribution, and reproduction in any medium, provided the original author and source are credited.
\end{abstract}

\section{ABSTRACT}

Purpose: The objective of this study is to evaluate the contribution of induction (IC) or adjuvant (AC) chemotherapy additional to concurrent chemoradiotherapy (CCRT) for patients with T3-4NO-1 nasopharyngeal carcinoma (NPC) in the era of intensity-modulate radiotherapy (IMRT).

Method and Materials: We retrospectively reviewed the data on 685 patients with newly diagnosed T3-4NO-1 NPC. Propensity score matching (PSM) method was used to match patients. Survival outcomes between different groups were calculated by Kaplan-Meier method and compared using log-rank test. Cox proportional hazard model was adopted to establish independent prognostic factors.

Results: In total, 236 pairs were selected from the primary cohort. Univariate analysis revealed 3-year overall survival (OS) $(90.8 \%$ vs. $90.3 \%, P=0.820)$, distant failure-free survival (DFFS) $(87.3 \%$ vs. $89.4 \%, P=0.896)$ and locoregional failurefree survival (LRFFS) $(95.4 \%$ vs. $93.0 \%, P=0.311)$ rates were comparable between CCRT plus IC/AC and CCRT alone groups. Multivariate analysis found that treatment group was not an independent prognostic factors for OS (HR, 0.964; 95\% CI, 0.6201.499; $P=0.869)$, DFFS (HR, 1.036; 95\% CI, 0.626-1.714; $P=0.890)$ and LRFFS (HR, 0.670; 95\% CI, 0.338-1.327; $P=0.250$ ). Further subgroup analysis according to overall stage also obtained similar results.

Conclusion: Patients with T3-4NO-1 NPC receiving CCRT could not benefit from additional induction or adjuvant chemotherapy in the era of IMRT.

\section{INTRODUCTION}

Nasopharyngeal carcinoma (NPC) is a head and neck malignancy that is endemic in South East Asia and Southern China [1-3], but relatively rare in Europe and the United States [2]. Unlike other head and neck cancers, radical surgery is not a treatment option for NPC because of its anatomic location. Nevertheless, NPC is highly sensitive to radiotherapy, and this treatment modality has been deemed the only curative strategy for non-disseminated disease. Treatment outcomes of early stage disease are usually excellent; however, the control of advanced NPC is challenging, and the condition has a 5 -year overall survival (OS) of 67-79\% [4, 5]. Therefore, much attention has been paid to locoregionally advanced disease, which accounts for $60-70 \%$ of all cases [6]

Since the Intergroup 0099 study [7] firstly reported a survival benefit from the combined strategy of radiotherapy with chemotherapy, concurrent chemoradiotherapy (CCRT) with or without adjuvant chemotherapy (AC) has been 
established as the standard treatment for locoregionally advanced NPC [8-13]. For the last two decades, induction chemotherapy (IC) administered before radiotherapy has received much attention [14-20] because it improves patient compliance and enables the early eradication of micrometastases. A recent network meta-analysis of individual patient data revealed that $\mathrm{IC}$ or $\mathrm{AC}$ in addition to CCRT can improve distant control or OS [21] in patients with advanced NPC. However, distant control and OS differ significantly between patients with different $\mathrm{N}$ stages [22]. Therefore, there is a lack of consensus among clinicians on the necessity of chemotherapy additional to CCRT in patients with N0-1-category locoregionally advanced NPC because this proportion of patients presents a relatively low rate of distant failure. Notably, previous studies usually recruited all patients with stage III and IVA-B disease and did not characterize this issue. This urgently needs to be addressed because additional of chemotherapy means more toxicities and heavier economic burden. Hence, we conducted this retrospective study to compare CCRT plus IC and/or AC with CCRT alone using propensity score matching (PSM) method [23].

\section{RESULTS}

\section{Baseline characteristics}

Among the primary cohort of 685 patients, there were $510(74.5 \%)$ male and $175(25.5 \%)$ female patients, carrying a ratio of 2.9:1. The median age was 49 (18-76) years-old. In total, 325 (47.4\%) patients received CCRT alone and $360(52.6 \%)$ patients received CCRT plus IC and/or AC. Additionally, 343 (50.1\%) and 342 (49.9\%) patients had stage III and IV disease, respectively. After matching, 236 pairs were selected by PSM and the baseline characteristics were summarized in Table 1. Obviously, host and tumor factors were well balanced between these two groups $(P>0.05$ for all rates). Moreover, no significant difference was observed between patients receiving CCRT with or without $\mathrm{IC} /$ AC with regard to concurrent chemotherapy regimens $(P$ $=0.771)$. Among the selected 236 patients, $156(66.1 \%)$ patients received IC and $80(33.9 \%)$ patients received AC. For IC, 58 (37.2\%) and $98(62.8 \%)$ patients received 2 and 3 cycles, respectively. For AC, most of patients received 2 cycles and only $20(8.5 \%)$ patients received 3 cycles. With regard to concurrent chemotherapy, all the patients completed the assigned two cycles although some patients experienced dose reduction.

\section{Treatment failure}

By the last visit (July 20, 2016), 40 (8.5\%) patients were lost to follow-up and the median follow-up duration for the selected 236 pairs was 51.1 months (range, 1.07148.0 months). Overall, $20(8.5 \%)$ in the CCRT alone group and $15(6.4 \%)$ in the CCRT plus IC/AC group experienced locoregional recurrence $(P=0.380)$, and $31(13.1 \%)$ in the CCRT group and $32(13.6 \%)$ in the CCRT plus IC/AC group developed distant metastasis $(P=0.892)$. Consequently, 80 deaths in total were observed with $40(16.9 \%)$ in each group $(P=1.000)$.

\section{Survival outcomes}

The estimated 3-year OS, distant failure-free survival (DFFS) and locoregional failure-free survival (LRFFS) rates for the whole cohort were 90.6\%, 88.4\% and $94.2 \%$, respectively. In comparison with the CCRT alone group, the CCRT plus IC/AC group achieved similar 3 -year OS (90.8\% vs. 90.3\%, $P=0.820$; Figure 1A), DFFS (87.3\% vs. $89.4 \%, P=0.896$; Figure $1 \mathrm{~B})$ and LRFFS (95.4\% vs. 93.0\%, $P=0.311$; Figure $1 \mathrm{C}$ ) rates.

Multivariate analysis was performed to adjust for various factors and identify independent prognostic factors (Table 2). When entered into this model, treatment group (CCRT plus IC/AC vs. CCRT) was still not established as an independent prognostic factor for OS (HR, 0.964; 95\% CI, 0.620-1.499; $P=0.869$ ), DFFS (HR, 1.036; 95\% CI, $0.626-1.714 ; P=0.890)$ and LRFFS (HR, 0.670; 95\% CI, $0.338-1.327 ; P=0.250)$. Results of multivariate analysis including all the prognostic factors were summarized in Supplementary Table 1.

\section{Subgroup analysis}

As presented by the results of multivariate analysis, overall stage (IV vs. III) was a predictor for OS and DFFS. We therefore performed stratified analysis in patients with T3N0-1 and T4N0-1 disease; 140 and 152 pairs were selected by PSM. Among patients with T3N0-1 disease, the 3 -year OS $(92.8 \%$ vs. $90.6 \% ; P=0.300$; Figure $2 \mathrm{~A})$, DFFS $(92.7 \%$ vs. 91.1\%; $P=0.308$; Figure $2 \mathrm{~B})$ and LRFFS (94.6\% vs. $92.2 \% ; P=0.644$; Figure 2C) rates were comparable between CCRT plus IC/AC and CCRT alone groups. Multivariate analysis did not identify treatment group as an independent prognostic factor for all the endpoints (Table 3).

With regard to patients with stage T4N0-1 disease, the 3 -year OS (87.1\% vs. $86.8 \% ; P=0.465$; Figure $3 \mathrm{~A})$, DFFS (84.5\% vs. $83.6 \% ; P=0.390$; Figure $3 \mathrm{~B})$ and LRFFS (95.7\% vs. $92.0 \% ; P=0.548$; Figure 3C) rates did not differ significantly between CCRT plus IC/AC and CCRT alone groups. Similar as the results of univariate analysis, multivariate analysis revealed treatment group still had no prognostic value (Table 3 ).

\section{DISCUSSION}

In our study, we firstly compared CCRT plus IC/AC with CCRT alone to evaluate the contribution of additional chemotherapy to CCRT in patients with T3-4N0-1 NPC, 
Table 1: Baseline characteristics of the 236 pairs with T3-4N0-1 NPC

\begin{tabular}{|c|c|c|c|}
\hline Characteristics & $\begin{array}{c}\text { CCRT plus IC/AC } \\
\text { No. }(\%)\end{array}$ & CCRT alone No. (\%) & $P$ \\
\hline Median age (y, range) & $48(18-74)$ & $50(18-76)$ & $0.156^{\mathrm{a}}$ \\
\hline Gender & & & $0.655^{b}$ \\
\hline Male & $183(77.5)$ & $187(79.2)$ & \\
\hline Female & $53(22.5)$ & $49(20.8)$ & \\
\hline Smoking & & & $0.639^{b}$ \\
\hline Yes & $97(41.1)$ & $92(40.0)$ & \\
\hline No & $139(58.9)$ & $144(60.0)$ & \\
\hline Drinking & & & $0.414^{b}$ \\
\hline Yes & $34(14.4)$ & $28(11.9)$ & \\
\hline No & $202(85.6)$ & $208(88.1)$ & \\
\hline KPS & & & $0.918^{b}$ \\
\hline$\geq 90$ & $172(72.9)$ & $171(72.5)$ & \\
\hline$\leq 80$ & $64(27.1)$ & $65(27.5)$ & \\
\hline Median LDH (range, U/L) & $177(111-516)$ & $171(109-514)$ & $0.893^{\mathrm{a}}$ \\
\hline $\mathrm{T}_{\text {category }}{ }^{\mathrm{c}}$ & & & $0.519^{b}$ \\
\hline T3 & $123(52.1)$ & $116(49.2)$ & \\
\hline $\mathrm{T} 4$ & $113(47.9)$ & $120(50.8)$ & \\
\hline $\mathrm{N}_{\text {category }}{ }^{\mathrm{c}}$ & & & $0.896^{b}$ \\
\hline No & $34(14.4)$ & $35(14.8)$ & \\
\hline N1 & $202(85.6)$ & $201(85.2)$ & \\
\hline Overall stage $^{c}$ & & & $0519^{b}$ \\
\hline III & $123(52.1)$ & $116(49.2)$ & \\
\hline IV & $113(47.9)$ & $120(50.8)$ & \\
\hline Concurrent chemotherapy regimen & & & $0.771^{\mathrm{b}}$ \\
\hline $\mathrm{PF}$ & $80(33.9)$ & $83(35.2)$ & \\
\hline $\mathrm{TP}$ & $156(66.1)$ & $153(64.8)$ & \\
\hline Locoregional recurrence & $15(6.4)$ & $20(8.5)$ & 0.380 \\
\hline Distant metastasis & $32(13.6)$ & $31(13.1)$ & 0.892 \\
\hline Death & 40 (16.9) & $40(16.9)$ & 1.000 \\
\hline
\end{tabular}

$\mathrm{NPC}=$ nasopharyngeal carcinoma; CCRT = concurrent chemoradiotherapy; $\mathrm{IC}=$ induction chemotherapy; $\mathrm{AC}=$ adjuvant chemotherapy; KPS = karnofsky performance score; LDH = lactate dehydrogenase; $\mathrm{PF}=$ cisplatin plus fluorouracil; TP= docetaxel plus cisplatin.

a P-values were calculated by non-parametric test.

${ }^{b} P$-values were calculated by Chi-square test.

${ }^{c}$ According to the $7^{\text {th }}$ edition of AJCC/UICC staging system.

and the results revealed induction or adjuvant docetaxel plus cisplatin with fluorouracil (TPF) or docetaxel plus cisplatin (TP) could not further improve survival outcomes of 3-year OS, DFFS and LRFFS. Furthermore, stratified analysis according to overall stage also obtained similar results. By using PSM, potential bias may be avoided and the results should be reliable.

Currently, CCRT followed by AC is still the recommended treatment regimen for advanced NPC. Nevertheless, induction chemotherapy is also widely used 
Table 2: Results of multivariate analysis for 236 pairs with T3-4N0-1 NPC

\begin{tabular}{|c|c|c|c|}
\hline Endpoints & Variable & HR $(95 \% \mathrm{CI})$ & $P^{a}$ \\
\hline $\mathrm{OS}^{\mathrm{b}}$ & $\begin{array}{c}\text { Treatment group, CCRT plus IC/AC vs. CCRT } \\
\text { alone }\end{array}$ & $0.964(0.620-1.499)$ & 0.869 \\
\hline \multirow{3}{*}{ DFFS $^{c}$} & Overall stage, IV vs. III & $2.682(1.289-5.580)$ & 0.008 \\
\hline & $\begin{array}{c}\text { Treatment group, CCRT plus IC/AC vs. CCRT } \\
\text { alone }\end{array}$ & $1.036(0.626-1.714)$ & 0.890 \\
\hline & Overall stage, IV vs. III & $2.099(1.139-3.868)$ & 0.005 \\
\hline LRFFS $^{d}$ & $\begin{array}{l}\text { Treatment group, CCRT plus IC/AC vs. CCRT } \\
\text { alone }\end{array}$ & $0.670(0.338-1.327)$ & 0.250 \\
\hline
\end{tabular}

$\mathrm{NPC}=$ nasopharyngeal carcinoma; OS = overall survival; DFFS = distant failure-free survival; LRFFS = locoregional failure-free survival; $\mathrm{HR}=$ hazard ratio; $\mathrm{CI}=$ confidence interval; $\mathrm{CCRT}=$ concurrent chemoradiotherapy; $\mathrm{IC}=$ induction chemotherapy; $\mathrm{AC}=$ adjuvant chemotherapy.

${ }^{a}$ Multivariate $P$-values were calculated using an adjusted Cox proportional-hazards model with backward elimination and the following parameters: age $(\geq 49 y$ vs. $<49 y$ ), gender (male vs. female), smoking (yes vs. no), drinking (yes vs. no), KPS ( $\geq 90$ vs. $\leq 80)$, N category (N1 vs. N0), overall stage (IV vs. III), concurrent chemotherapy regimen (TP vs. PF) and treatment group (CCRT plus IC/AC vs. CCRT).

${ }^{\mathrm{b}}$ Forty patients in the CCRT and 40 patients in the CCRT plus IC/AC were dead $(P=1.000)$.

c Thirty-one in the CCRT and 32 patients in the CCRT plus IC/AC experienced distant metastasis $(P=0.892)$.

d Twenty in the CCRT and 15 patients in the CCRT plus IC/AC developed locoregional recurrence $(\mathrm{P}=0.380)$.
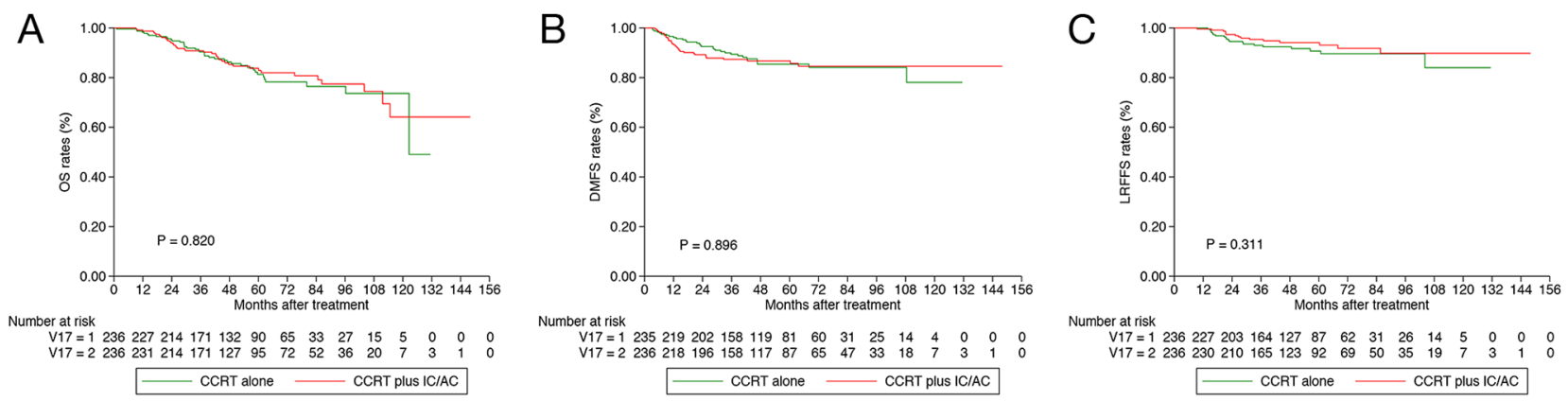

Figure 1: Kaplan-Meier OS (A), DFFS (B) and LRFFS (C) curves for 236 pairs with T3-4N0-1 NPC stratifies as CCRT plus $\mathrm{IC} / \mathrm{AC}$ and CCRT alone groups. OS = overall survival; DFFS = distant failure-free survival; LRFFS = locoregional failure-free survival; $\mathrm{NPC}=$ nasopharyngeal carcinoma; CCRT $=$ concurrent chemoradiotherapy; $\mathrm{IC}=$ induction chemotherapy; $\mathrm{AC}=$ adjuvant chemotherapy .
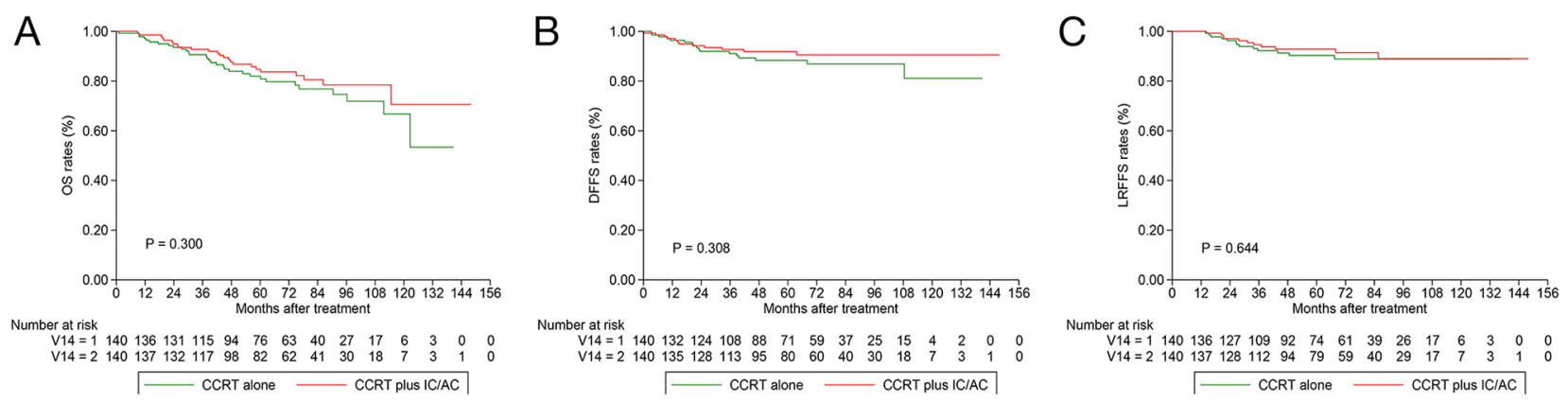

Figure 2: Kaplan-Meier OS (A), DFFS (B) and LRFFS (C) curves for 140 pairs with T3N0-1 NPC stratifies as CCRT plus IC/AC and CCRT alone groups. OS = overall survival; DFFS = distant failure-free survival; LRFFS = locoregional failure-free survival; NPC = nasopharyngeal carcinoma; CCRT = concurrent chemoradiotherapy; IC = induction chemotherapy; AC = adjuvant chemotherapy. 
Table 3: Subgroup multivariate analysis stratified by overall stage

\begin{tabular}{|c|c|c|c|}
\hline Endpoints & Variable & HR $(95 \% C I)$ & $P^{a}$ \\
\hline \multicolumn{4}{|l|}{ Stage III } \\
\hline \multirow[t]{2}{*}{$\mathrm{OS}^{\mathrm{b}}$} & $\begin{array}{c}\text { Treatment group, CCRT plus IC/AC vs. CCRT } \\
\text { alone }\end{array}$ & $0.835(0.488-1.430)$ & 0.511 \\
\hline & Age, $\geq 49 y$ vs. $<49 y$ & $2.074(1.183-3.637)$ & 0.011 \\
\hline DFFS $^{\mathrm{c}}$ & $\begin{array}{c}\text { Treatment group, CCRT plus IC/AC vs. CCRT } \\
\text { alone }\end{array}$ & $0.712(0.338-1.499)$ & 0.372 \\
\hline LRFFS $^{d}$ & $\begin{array}{c}\text { Treatment group, CCRT plus IC/AC vs. CCRT } \\
\text { alone }\end{array}$ & $0.821(0.367-1.835)$ & 0.630 \\
\hline \multicolumn{4}{|l|}{ Stage IV } \\
\hline \multirow[t]{2}{*}{$\mathrm{OS}^{\mathrm{b}}$} & $\begin{array}{c}\text { Treatment group, CCRT plus IC/AC vs. CCRT } \\
\text { alone }\end{array}$ & $1.234(0.795-1.929)$ & 0.344 \\
\hline & Age, $\geq 49 y$ vs. $<49 y$ & $1.861(1.157-2.992)$ & 0.010 \\
\hline DFFS $^{c}$ & $\begin{array}{c}\text { Treatment group, CCRT plus IC/AC vs. CCRT } \\
\text { alone }\end{array}$ & $0.761(0.452-1.284)$ & 0.307 \\
\hline LRFFS $^{\mathrm{d}}$ & $\begin{array}{c}\text { Treatment group, CCRT plus IC/AC vs. CCRT } \\
\text { alone }\end{array}$ & $0.822(0.388-1.743)$ & 0.609 \\
\hline
\end{tabular}

$\mathrm{OS}=$ overall survival; DFFS = distant failure-free survival; LRFFS = locoregional failure-free survival; HR = hazard ratio; $\mathrm{CI}=$ confidence interval; $\mathrm{CCRT}=$ concurrent chemoradiotherapy; $\mathrm{IC}=$ induction chemotherapy; $\mathrm{AC}=$ adjuvant chemotherapy.

a Multivariate $P$-values were calculated using an adjusted Cox proportional-hazards model with backward elimination and the following parameters: age ( $\geq 49 y$ vs. $<49 y$ ), gender (male vs. female), smoking (yes vs. no), drinking (yes vs. no), KPS $(\geq 90$ vs. $\leq 80)$, N category (N1 vs. N0), concurrent chemotherapy regimen (TP vs. PF) and treatment group (CCRT plus IC/ AC vs. CCRT).

b Thirty-one in the CCRT and 24 patients in CCRT plus IC/AC with stage III $(\mathrm{P}=0.292)$, and 38 in CCRT and 41 in CCRT plus IC/AC with stage IV $(\mathrm{P}=0.695)$ were dead.

c Seventeen in the CCRT and 12 patients in CCRT plus IC/AC with stage III $(\mathrm{P}=0.327)$, and 33 in CCRT and 25 in CCRT plus IC/AC with stage IV $(\mathrm{P}=0.243)$ experienced distant metastasis.

d Thirteen in the CCRT and 11 patients in CCRT plus IC/AC with stage III $(\mathrm{P}=0.669)$, and 16 in CCRT and 12 in CCRT plus IC/AC with stage IV $(\mathrm{P}=0.428)$ developed locoregional recurrence.

A

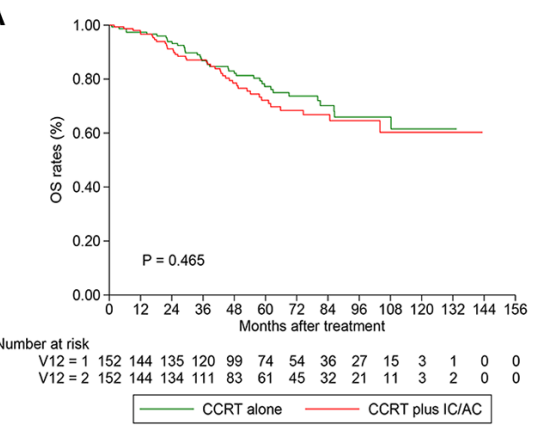

B

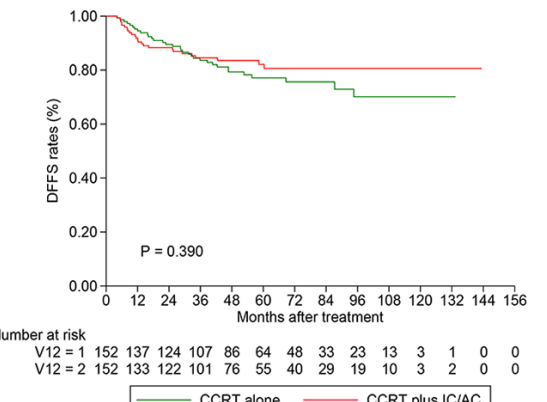

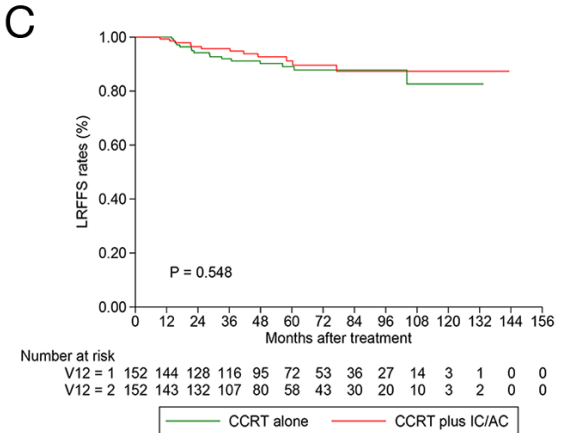

Figure 3: Kaplan-Meier OS (A), DFFS (B) and LRFFS (C) curves for 152 pairs with T4N0-1 NPC stratifies as CCRT plus $\mathrm{IC} / \mathrm{AC}$ and CCRT alone groups. OS = overall survival; DFFS = distant failure-free survival; LRFFS = locoregional failurefree survival; NPC = nasopharyngeal carcinoma; CCRT = concurrent chemoradiotherapy; IC = induction chemotherapy; $\mathrm{AC}$ = adjuvant chemotherapy. 
at practice for its better compliance and early eradication of micrometastasis. Therefore, CCRT with IC or AC has come as a preferable treatment option at practice. However, distant control and overall survival significantly differ between patients with different $\mathrm{N}$ categories [22]. Therefore, it may be unlikely for all the advanced patients to receive the same treatment plan since they are at different risks. Possibly, patients with N0-1 category have lower tumor burden and therefore have better prognosis. Hence, additional chemotherapy to CCRT may be futile for this low-risk group. In our study, we clarified that patients with T3-4N0-1 disease could not benefit from IC or AC. In the study by International Nasopharynx Cancer Study Group [17], a positive effect of progression-free survival was achieved in patients with stage IV ( $\geq$ N2), indicating that high-risk patients would benefit from additional induction chemotherapy. Moreover, in the study by Chen et al. [11], no significantly survival difference was found between the CCRT plus AC and CCRT alone groups. This was mainly attributed to the high proportion $(65 \%)$ of low-risk patients (stage III) recruited for the study, which diluted the survival benefit from AC. Given all these, patients with T3-4N0-1 disease should be grouped as low-risk, and additional chemotherapy as IC or AC should not be delivered.

Notably, although different regimens like TPF and TP were used as induction and adjuvant chemotherapy, it may be less likely to affect the conclusions of this study because both TP [16] and TPF [19] have been proven to be effective regimens in advanced NPC. Moreover, there is no evidence showing the efficacy difference between these two regimens. In our study, we combined induction and adjuvant chemotherapy together in the CCRT plus IC/AC group because the survival difference between inductionconcurrent and concurrent-adjuvant chemotherapy sequences has not been clarified by any randomized trials so far. Possibly, they were equally effective as pointing out by a recent network meta-analysis [21]. Therefore, it should be reasonable to combine IC and AC together as a whole group. Concurrent chemotherapy used in our study were cisplatin-based regimens including TP and cisplatin plus fluorouracil (PF), which was firstly used in the study by Lin et al. [13]. Although different regimens were used, they were well balanced between CCRT plus IC/AC and CCRT alone groups. Moreover, multivariate analysis did not identify it as an independent prognostic factor. Therefore, the concurrent chemotherapy regimens would also have no impact on the conclusion.

The main strengthen of our study is the adoption of PSM method and multivariate analysis to evaluate the contribution of additional chemotherapy such as induction or/and adjuvant chemotherapy for patients with T3-4N0-1 disease; this could address the potential disadvantages of retrospective study like divergent confounders, selection bias and treatment heterogeneity [23]. Based on the results of this study, we suggested that CCRT may be enough for patients with T3-4N0-1 disease and additional chemotherapy could not bring further benefit. However, limitations of this study should also be acknowledged. First, the data was retrospectively collected from a single center. Second, the sample may be insufficient because patients with T3-4N0-1 have satisfactory survival outcomes and larger sample, especially in the subgroup analysis, is warrant to find out the difference. Third, the chemotherapy regimens used during CCRT is cisplatinbased double agents which may decrease the compliance. Therefore, the conclusions should be understood discreetly. Furthermore, powerfully prognostic biomarker like pre-treatment plasma Epstein-Barr virus (EBV) DNA [24-27] not considered because most of patients were treated at an early time when test of plasma EBV DNA was not available. In the studies by Peng et al. [28] and Du et al. [29], plasma EBV DNA was found to be an effective risk stratification factor. Therefore, future management of patients with T3-4N0-1 NPC should also take plasma EBV DNA into consideration.

\section{CONCLUSIONS}

In summary, our study firstly showed that patients with T3-4N0-1 NPC receiving CCRT may not benefit from additional induction or adjuvant chemotherapy. Future prospective studies consisting large sample and plasma EBV DNA are warrant to confirm the results of this study.

\section{MATERIALS AND METHODS}

\section{Study patient selection}

We retrospectively reviewed the data on 685 consecutive patients with newly diagnosed, nondisseminated NPC treated at Nanjing Medical University Affiliated Cancer Hospital of China between May 2004 and October 2014. Patients meeting the following criteria were included in this study: (1) age 18 years or older; (2) T3-4N0-1 disease; (3) receiving CCRT with or without IC/ $\mathrm{AC}$; (4) no malignant tumor history and non-anticancer treatment previously. Written informed consent was obtained from all the patients before treatment, and this study was approved by the Research Ethics Committee of Jiangsu Cancer Hospital.

\section{Pre-treatment staging workup}

In our hospital, patients at initial diagnosis received staging workup including clinical examinations of head and neck regions, fibreoptic nasopharyngoscopy, magnetic resonance imaging (MRI) or contrast-enhanced computed tomography (CT) of the head and neck to evaluate the extent of the primary tumor and regional lymph nodes. Bone scintigraphy, chest radiography or contrast-CT, and ultrasonography of the abdominal region 
would also be performed to identify distant metastasis. 18F-fluorodeoxyglucose (18F-FDG) positron emission tomography (PET)-CT would also be performed if clinically indicated, and 131 (19.1\%) patients received this test. All patients were restaged according to the $7^{\text {th }}$ edition of the International Union against Cancer/American Joint Committee on Cancer (UICC/AJCC) system [30].

\section{Radiotherapy and chemotherapy}

All the patients received radical intensity-modulated radiotherapy (IMRT) using simultaneous integrated boost (SIB) in our center. A total prescribed doses of 66-75Gy/3135 fractions to the planning target volume (PTV) of primary gross tumor volume (GTVnx), 65-75Gy/32-35 fractions to the PTV of metastatic lymph nodes (GTVnd), 56-60Gy/30 fractions to the PTV of high-risk clinical target volume (CTV1) and 50Gy/30 fractions to the PTV of low-risk clinical target volume (CTV2) were delivered with first 30 fractions to CTV1/CTV2 and then a boost to PTV of GTVnx and GTVnd for patients with locally or regionally residual tumor after prescribed dose. In total, $10(4.2 \%)$ patients in the IC/AC + CCRT group and $13(5.1 \%)$ in the CCRT alone group received boost radiation dose $(\mathrm{P}=0.662)$.

Induction or adjuvant chemotherapy were performed for using platinum-based regimens including docetaxel $\left(75 \mathrm{mg} / \mathrm{m}^{2} \mathrm{~d} 1\right)$ with cisplatin $\left(80 \mathrm{mg} / \mathrm{m}^{2}\right.$ in total for $\left.\mathrm{d} 1-3\right)$ or triplet of docetaxel $\left(60 \mathrm{mg} / \mathrm{m}^{2} \mathrm{~d} 1\right)$ and cisplatin $(80 \mathrm{mg} /$ $\mathrm{m}^{2}$ in total for $\left.\mathrm{d} 1-3\right)$ plus 5 -fluorouracil $\left(1000 \mathrm{mg} / \mathrm{m}^{2} / \mathrm{d}\right.$ d1-d5) every three weeks for 2 to 3 cycles. Concurrent chemotherapy regimens mainly consisted of cisplatin $\left(80 \mathrm{mg} / \mathrm{m}^{2}\right.$ in total for d1-3) plus fluorouracil $\left(400 \mathrm{mg} / \mathrm{m}^{2} / \mathrm{d}\right.$ $\mathrm{d} 1-\mathrm{d} 4)$ or docetaxel $\left(75 \mathrm{mg} / \mathrm{m}^{2} \mathrm{~d} 1\right)$ plus cisplatin $\left(80 \mathrm{mg} / \mathrm{m}^{2}\right.$ in total for d1-3) at 3-week interval for two cycles.

\section{Follow-up}

Follow-up was measured from first day of treatment to last examination or death. Patients were followed by clinical physical examination, nasopharyngoscopy, CT scan or MRI of the head and neck region, ultrasonography of the abdomen and chest X-ray every 3 months during the first 2 years, then every 6 to 12 months thereafter (or until death) even with last normal findings. The primary endpoint is OS (time to death from any reason), and other endpoints included DFFS (time to distant metastasis) and LRFFS (time to local or regional recurrence or both).

\section{Statistical analysis}

PSM was performed using the Nearest Neighbor method at a 1:1 ratio. Logit estimation was used and the following variables were included to match patients with the caliper of 0.1: age, gender, smoking, drinking, karnofsky performance score (KPS), lactate dehydrogenase (LDH), T category, N category, overall stage and concurrent chemotherapy regimen. Failure events in two groups were not considered when matching patients. Non-parametric and Chi-square test was used to compare continuous and categorical variables between the two groups. Kaplan-Meier method was adopted to calculated survival outcomes and difference was compared by log-rank test. Multivariate analysis using the Cox proportional hazards model was performed to estimate hazard ratios (HRs), 95\% confidence intervals (CIs) and identify independent prognostic factors.

\section{CONFLICTS OF INTEREST}

The authors declare no competing interest.

\section{GRANT SUPPORT}

This work received funding from National Natural Science Foundation of China (No. 81672989), Jiangsu Clinical medicine Science and Technology Special Fund (BL2014091), Jiangsu Provincial Commission of Health and Family Planning Youth Research Project (Q201601), National Natural Science Foundation of China (No. 81602381) and National Science Foundation of Jiangsu Province (BK 20151019).

\section{REFERENCES}

1. Cao SM, Simons MJ, Qian CN. The prevalence and prevention of nasopharyngeal carcinoma in China. Chin $\mathrm{J}$ Cancer. 2011; 30:114-119.

2. Ferlay J, Soerjomataram I, Dikshit R, Eser S, Mathers C, Rebelo M, Parkin DM, Forman D, Bray F. Cancer incidence and mortality worldwide: sources, methods and major patterns in GLOBOCAN 2012. Int J Cancer. 2015; 136:E359-386.

3. Razak AR, Siu LL, Liu FF, Ito E, O'Sullivan B, Chan K. Nasopharyngeal carcinoma: the next challenges. Eur J Cancer. 2010; 46:1967-1978.

4. Sun X, Su S, Chen C, Han F, Zhao C, Xiao W, Deng $\mathrm{X}$, Huang S, Lin C, Lu T. Long-term outcomes of intensity-modulated radiotherapy for 868 patients with nasopharyngeal carcinoma: an analysis of survival and treatment toxicities. Radiother Oncol. 2014; 110:398-403.

5. Yi JL, Gao L, Huang XD, Li SY, Luo JW, Cai WM, Xiao JP, Xu GZ. Nasopharyngeal carcinoma treated by radical radiotherapy alone: ten-year experience of a single institution. Int J Radiat Oncol Biol Phys. 2006; 65:161-168.

6. Mao YP, Xie FY, Liu LZ, Sun Y, Li L, Tang LL, Liao XB, Xu HY, Chen L, Lai SZ, Lin AH, Liu MZ, Ma J. Re-evaluation of 6th edition of AJCC staging system for nasopharyngeal carcinoma and proposed improvement based on magnetic resonance imaging. Int J Radiat Oncol Biol Phys. 2009; 73:1326-1334.

7. Al-Sarraf M, LeBlanc M, Giri PG, Fu KK, Cooper J, Vuong T, Forastiere AA, Adams G, Sakr WA, Schuller DE, Ensley 
JF. Chemoradiotherapy versus radiotherapy in patients with advanced nasopharyngeal cancer: phase III randomized Intergroup study 0099. J Clin Oncol. 1998; 16:1310-1317.

8. Baujat B, Audry H, Bourhis J, Chan AT, Onat H, Chua DT, Kwong DL, Al-Sarraf M, Chi KH, Hareyama M, Leung SF, Thephamongkhol K, Pignon JP; MAC-NPC Collaborative Group. Chemotherapy in locally advanced nasopharyngeal carcinoma: an individual patient data meta-analysis of eight randomized trials and 1753 patients. Int J Radiat Oncol Biol Phys. 2006; 64:47-56.

9. Chan AT, Leung SF, Ngan RK, Teo PM, Lau WH, Kwan WH, Hui EP, Yiu HY, Yeo W, Cheung FY, Yu KH, Chiu $\mathrm{KW}$, Chan DT, et al. Overall survival after concurrent cisplatin-radiotherapy compared with radiotherapy alone in locoregionally advanced nasopharyngeal carcinoma. J Natl Cancer Inst. 2005; 97:536-539.

10. Chan AT, Teo PM, Ngan RK, Leung TW, Lau WH, Zee B, Leung SF, Cheung FY, Yeo W, Yiu HH, Yu KH, Chiu KW, Chan DT, et al. Concurrent chemotherapy-radiotherapy compared with radiotherapy alone in locoregionally advanced nasopharyngeal carcinoma: progression-free survival analysis of a phase III randomized trial. J Clin Oncol. 2002; 20:2038-2044.

11. Chen L, Hu CS, Chen XZ, Hu GQ, Cheng ZB, Sun Y, Li WX, Chen YY, Xie FY, Liang SB, Chen Y, Xu TT, Li $\mathrm{B}$, et al. Concurrent chemoradiotherapy plus adjuvant chemotherapy versus concurrent chemoradiotherapy alone in patients with locoregionally advanced nasopharyngeal carcinoma: a phase 3 multicentre randomised controlled trial. Lancet Oncol. 2012; 13:163-171.

12. Chen YP, Wang ZX, Chen L, Liu X, Tang LL, Mao YP, Li WF, Lin AH, Sun Y, Ma J. A Bayesian network metaanalysis comparing concurrent chemoradiotherapy followed by adjuvant chemotherapy, concurrent chemoradiotherapy alone and radiotherapy alone in patients with locoregionally advanced nasopharyngeal carcinoma. Ann Oncol. 2015; 26:205-211.

13. Lin JC, Jan JS, Hsu CY, Liang WM, Jiang RS, Wang WY. Phase III study of concurrent chemoradiotherapy versus radiotherapy alone for advanced nasopharyngeal carcinoma: positive effect on overall and progression-free survival. J Clin Oncol. 2003; 21:631-637.

14. Chua DT, Sham JS, Choy D, Lorvidhaya V, Sumitsawan Y, Thongprasert S, Vootiprux V, Cheirsilpa A, Azhar T, Reksodiputro AH. Preliminary report of the AsianOceanian Clinical Oncology Association randomized trial comparing cisplatin and epirubicin followed by radiotherapy versus radiotherapy alone in the treatment of patients with locoregionally advanced nasopharyngeal carcinoma. AsianOceanian Clinical Oncology Association Nasopharynx Cancer Study Group. Cancer. 1998; 83:2270-2283.

15. Hong RL, Ting LL, Ko JY, Hsu MM, Sheen TS, Lou PJ, Wang CC, Chung NN, Lui LT. Induction chemotherapy with mitomycin, epirubicin, cisplatin, fluorouracil, and leucovorin followed by radiotherapy in the treatment of locoregionally advanced nasopharyngeal carcinoma. J Clin Oncol. 2001; 19:4305-4313.

16. Hui EP, Ma BB, Leung SF, King AD, Mo F, Kam MK, Yu BK, Chiu SK, Kwan WH, Ho R, Chan I, Ahuja AT, Zee BC, Chan AT. Randomized phase II trial of concurrent cisplatinradiotherapy with or without neoadjuvant docetaxel and cisplatin in advanced nasopharyngeal carcinoma. J Clin Oncol. 2009; 27:242-249.

17. International Nasopharynx Cancer Study G, Trial VI. Preliminary results of a randomized trial comparing neoadjuvant chemotherapy (cisplatin, epirubicin, bleomycin) plus radiotherapy vs. radiotherapy alone in stage $\operatorname{IV}(>$ or = N2, M0) undifferentiated nasopharyngeal carcinoma: a positive effect on progression-free survival. Int J Radiat Oncol Biol Phys. 1996; 35:463-469.

18. Ma J, Mai HQ, Hong MH, Min HQ, Mao ZD, Cui NJ, Lu TX, Mo HY. Results of a prospective randomized trial comparing neoadjuvant chemotherapy plus radiotherapy with radiotherapy alone in patients with locoregionally advanced nasopharyngeal carcinoma. J Clin Oncol. 2001; 19:1350-1357.

19. Sun Y, Li WF, Chen NY, Zhang N, Hu GQ, Xie FY, Sun Y, Chen XZ, Li JG, Zhu XD, Hu CS, Xu XY, Chen $\mathrm{YY}$, et al. Induction chemotherapy plus concurrent chemoradiotherapy versus concurrent chemoradiotherapy alone in locoregionally advanced nasopharyngeal carcinoma: a phase 3, multicentre, randomised controlled trial. Lancet Oncol. 2016; 17:1509-1520.

20. Tan T, Lim WT, Fong KW, Cheah SL, Soong YL, Ang MK, Ng QS, Tan D, Ong WS, Tan SH, Yip C, Quah D, Soo KC, Wee J. Concurrent chemo-radiation with or without induction gemcitabine, Carboplatin, and Paclitaxel: a randomized, phase $2 / 3$ trial in locally advanced nasopharyngeal carcinoma. Int J Radiat Oncol Biol Phys. 2015; 91:952-960.

21. Ribassin-Majed L, Marguet S, Lee AW, Ng WT, Ma J, Chan AT, Huang PY, Zhu G, Chua DT, Chen Y, Mai HQ, Kwong DL, Cheah SL, et al. What is the best treatment of locally advanced nasopharyngeal carcinoma? An individual patient data network meta-analysis. J Clin Oncol. 2016:JCO2016674119.

22. Mao YP, Liang SB, Liu LZ, Chen Y, Sun Y, Tang LL, Tian L, Lin AH, Liu MZ, Li L, Ma J. The N staging system in nasopharyngeal carcinoma with radiation therapy oncology group guidelines for lymph node levels based on magnetic resonance imaging. Clin Cancer Res. 2008; 14:7497-7503.

23. Austin PC. The relative ability of different propensity score methods to balance measured covariates between treated and untreated subjects in observational studies. Med Decis Making. 2009; 29:661-677.

24. Chan AT, Lo YM, Zee B, Chan LY, Ma BB, Leung SF, Mo F, Lai M, Ho S, Huang DP, Johnson PJ. Plasma EpsteinBarr virus DNA and residual disease after radiotherapy for undifferentiated nasopharyngeal carcinoma. J Natl Cancer Inst. 2002; 94:1614-1619. 
25. Lin JC, Wang WY, Chen KY, Wei YH, Liang WM, Jan JS, Jiang RS. Quantification of plasma Epstein-Barr virus DNA in patients with advanced nasopharyngeal carcinoma. N Engl J Med. 2004; 350:2461-2470.

26. Lin JC, Wang WY, Liang WM, Chou HY, Jan JS, Jiang RS, Wang JY, Twu CW, Liang KL, Chao J, Shen WC. Longterm prognostic effects of plasma epstein-barr virus DNA by minor groove binder-probe real-time quantitative PCR on nasopharyngeal carcinoma patients receiving concurrent chemoradiotherapy. Int J Radiat Oncol Biol Phys. 2007; 68:1342-1348.

27. Peng H, Guo R, Chen L, Zhang Y, Li WF, Mao YP, Sun Y, Zhang F, Liu LZ, Lin AH, Ma J. Prognostic impact of plasma epstein-barr virus DNA in patients with nasopharyngeal carcinoma treated using intensitymodulated radiation therapy. Sci Rep. 2016; 6:22000.
28. Peng H, Chen L, Li WF, Guo R, Zhang Y, Zhang F, Liu LZ, Tian L, Lin AH, Sun Y, Ma J. Prognostic value of neoadjuvant chemotherapy in locoregionally advanced nasopharyngeal carcinoma with low pre-treatment epsteinbarr virus DNA: a propensity-matched analysis. J Cancer. 2016; 7:1465-1471.

29. Du XJ, Tang LL, Chen L, Mao YP, Guo R, Liu X, Sun Y, Zeng MS, Kang TB, Shao JY, Lin AH, Ma J. Neoadjuvant chemotherapy in locally advanced nasopharyngeal carcinoma: defining high-risk patients who may benefit before concurrent chemotherapy combined with intensitymodulated radiotherapy. Sci Rep. 2015; 5:16664.

30. Edge SB, Compton CC. The American Joint Committee on Cancer: the 7 th edition of the AJCC cancer staging manual and the future of TNM. Ann Surg Oncol. 2010; 17:1471-1474. 